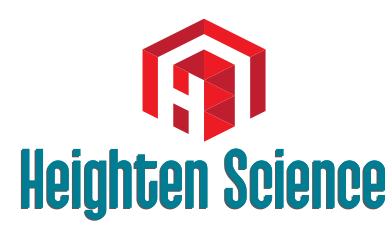

P U B L I C A T I O N S Corporation

\title{
Novel Non-invasive Management of Chronic Groin Pain from Fibrosed Contracted Inguinal Ligament
}

\author{
A Lokeshwar Raaju and N Ragunanthan* \\ Rathimed Speciality Hospital, Chennai, India
}

*Address for Correspondence: Dr. N Ragunanthan MS Orth, DNB Orth, MRCS, FRCS Orth, Rathimed Speciality Hospital, Q- 102, 3rd Avenue, Anna Nagar, Chennai, Tamil Nadu, India, E-mail: ragunanthan@rediffmail.com

Submitted: 28 September 2018

Approved: 11 October 2018

Published: 12 October 2018

Copyright: () 2018 Raaju AL, et al. This is an open access article distributed under the Creative Commons Attribution License, which permits unrestricted use, distribution, and reproduction in any medium, provided the original work is properly cited

Keywords: Chronic groin pain; Inguinal ligament fibrosis; Percutaneous needle release; Plateletrich plasma injection

Check for updates

\section{Abstract}

A 34-year-old male patient presented with the complaint of chronic pain in the left groin following left side testicular vein ligation for varicocele. Ilio-inguinal neurectomy and cremaster muscle division was done in another hospital for the pain but with no relief of pain. Patient on examination showed point tenderness in the left groin at the pubic tubercle. Finger Invagination test in the left was painful with severe tenderness. Investigation showed fibrosed contracted left distal inguinal ligament. Percutaneous Ultrasonographic (USG) guided inguinal ligament release and Platelet-Rich Plasma (PRP) injection relieved the pain completely. Post-procedure patient showed significant improvement of pain.

\section{Introduction}

Groin pain can be of sudden onset (acute), and persist over a long period (chronic), depending on the cause [1].

Groin pain can be as a result of trauma, infection, tumour, hernia, muscle strain, hip pathology, bursitis, fractures, radiating pain from the muscles and tendons of legs. In males, inflammation of testicles and other conditions affecting the scrotum can result in groin pain [1].

Groin pain is also known to occur postoperatively following the inguinal repair surgeries and surgery for varicocele [2,3]. Mild pain lasting for few days following surgery is not uncommon, but moderate/severe pain lasting for more than three months need to be considered and investigated to identify the cause and treat accordingly.

\section{Case Presentation}

We present a 34 years old male patient who came with complaints of pain in the left groin area for the past four years. For secondary infertility, Varicocele ligation on the left was done in 2010. After the procedure, the patient developed groin pain for which ilioinguinal neurectomy and cremaster muscle division was done in another hospital (2015). Pain was persistent and he presented to the Out-Patient Department of our hospital. Examination showed point tenderness in the left groin area at pubic tubercle. Finger invagination test showed severe tenderness in the left side mainly at the pubic tubercle and medial end of the inguinal ligament. MRI of groin with the hip joint was done, which revealed non-visualization of the left medial end of inguinal ligament suggestive of scar tissue/ adhesions. No evidence of hip pathology, muscle inflammation, osteitis pubis noted (Figure 1a,b). Blood serology for inflammatory markers was within normal limits. General surgeon opinion was obtained to rule out a hernia. Clinically no evidence of hernia was found. Under USG guidance local 
anaesthetic agent was infiltrated over the painful area. Point tenderness improved and finger invagination test was not painful.

Under USG guidance percutaneous needle release of the fibrosed ilioinguinal ligament followed by PRP injection in the left groin was done. Post-procedure, the patient pain settled down. Patient was started on inguinal stretching programme along with strengthening of abdominal wall muscles.

Patient was followed up for three months and advised to continue Groin Stretching and Anterior abdominal wall muscle strengthening exercises. The Patient had no complaints of pain and can do his daily routine activities without any limitations.

\section{Discussion}

The most common cause of groin pain is a muscle, tendon, or ligament strain.

Groin pain might occur immediately after an injury or the patient may present with pain of gradual onset over a period of weeks or even months. Causes of groin pain include the following: Osteitis pubis, Inguinal hernia, Adductor tendinitis, Bursitis, Epididymitis, Hydrocele, Avulsion fracture, Varicocele, Sciatica, Retractile testis, Spermatocele, Stress fracture, Swollen lymph nodes, Testicular tension, Orchitis, Urinary tract infection, Ilioinguinal neuroma, enthesopathy (tennis elbow of groin), Sportsman hernia (tear in inguinal ring), Symphysidysis, Symphysioliitis, Mesh Inguinodynia, hip pathology [2-5].

Groin pain is a recognized complication following groin surgeries like inguinal hernia repair varicocele surgery $[3,6,7]$.

The Anatomy of the Groin region is very complex, Consisting Inguinal Ligament, structures which are passing behind the ligament, the Inguinal Canal which is the oblique passage just above the medial half of the inguinal ligament with its structures passing through the canal and the medial end of the pubic tubercle called the Crest Of the pubis which provides attachment to the muscles like Conjoint tendon, Pyramidalis, Rectus abdominis and the external oblique muscle. The inguinal ligament extends from the anterior superior iliac Crest of Ilium to the Pubic tubercle of the pubic bone. It is formed by the Abdominal External oblique muscle aponeurosis and continues as the Fascia Lata of the thigh. Therefore, the pathology in this complex anatomic region of the groin causes difficulty in identifying the exact cause of pain [8].

In this particular patient, MRI groin and hip joint ruled out osteitis pubis, adductor tendinitis and other causes of groin pain. Clinically patient showed no evidence of an inguinal hernia. But MRI revealed poor visualization of the ilioinguinal ligament in the left groin probably due to the scar tissue/adhesions involving the ilioinguinal ligament probably because of the previous surgery (Figure 1a,b). Further, the patient on finger invagination test showed severe tenderness in the left side because of the thickened medial side of the ilioinguinal ligament at the site of pubic insertion.

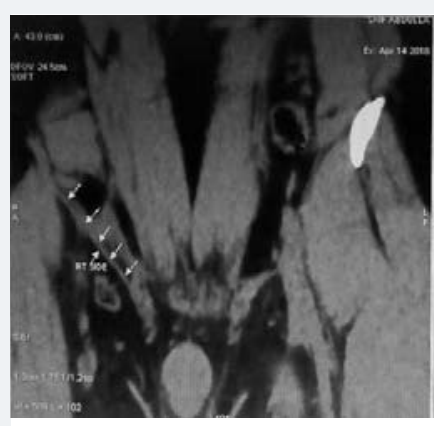

a)

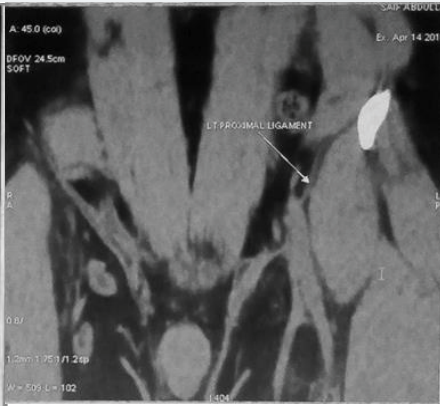

b)

Table 1: a): MRI showing Normal right-side inguinal ligament and b): non-visualized left distal inguinal ligament. 
Various procedures have been described for the management of groin pain which includes Laparoscopic inguinal ligament tenotomy and mesh reinforcement of the anterior abdominal wall [9], Open/Laparoscopic mesh removal and ilioinguinal neurectomy and replacement of mesh opposite to the location of the first mesh $[6,7,10]$. With these surgical procedures, if the pain persists, it is difficult to determine whether the pain is due to the mesh related complications like infection, mesh rejection, mesh migration or because of the initial pain the patient presented with. Also repeated re-explorations should be avoided considering the anaesthetic risks and the Surgical Morbidity.

In this patient the fibrosed thickened ilioinguinal ligament was released percutaneously along with Platelet-Rich Plasma injection. Steroid injection was not chosen because MRI didn't reveal any inflammation and multiple steroid injections can itself cause fibrosis. Considering the presence of various bioactive factors in platelet rich plasma, which favours cellular growth and tissue regeneration Platelet-rich plasma was injected locally [11]. Post-procedure after a follow up of three months period, the patient had no complaints of pain and no difficulty in undergoing his daily routine activities. Therefore, noninvasive management of groin pain should always be preferred first and failure of which surgical/invasive procedures can be considered.

\section{Conclusion}

This novel, technique of per-cutaneous release of fibrosed inguinal ligament can give good short-term results in chronic groin pain due to fibrosis of inguinal ligament particularly when combined with Bioactive Platelet-Rich Plasma. It can avoid invasive surgery like laparoscopic inguinal ligament release and mesh reinforcement, and its related complications. Limitation of the study is, case report of single patient and short term result (3 months).

\section{References}

1. Kasper D, Fauci A, Hauser S, Longo D, Jameson JL, et al. Harrison's Principles of Internal Medicine, 19th Ed. United States: McGraw-Hill Education, 2015. Ref.: https://goo.gl/LqYySB

2. Heise $\mathrm{CP}$, Starling JR. Mesh inguinodynia: a new clinical syndrome after inguinal herniorrhaphy? J Am Coll Surg. 1998; 187: 514-518. Ref.: https://goo.gl/eXoqnc

3. Kumar S, Wilson RG, Nixon SJ, Macintyre IM. Chronic pain after laparoscopic and open mesh repair of groin hernia. Br J Surg. 2002; 89: 1476-1479. Ref.: https://goo.gl/h4bm2Z

4. Ashby EC. Chronic obscure groin pain is commonly caused by enthesopathy: 'tennis elbow' of the groin. Br J Surg. 1994; 81: 1632-1634. Ref.: https://goo.gl/2WqZgd

5. Maarten JA. Surgical management of chronic inguinal pain syndromes. (University of Maastricht, September 29th 2011). Ref.: https://goo.gl/hKHRNx

6. Keller JE, Stefanidis D, Dolce CJ, lannitti DA, Kercher KW, et al. Combined open and laparoscopic approach to chronic pain after inguinal hernia repair. Am Surg. 2008; 74: 695-700. Ref.: https://goo.gl/Z9iP7a

7. Zwaans WA, Perquin CW, Loos MJ, Roumen RM, Scheltinga MR. Mesh Removal and Selective Neurectomy for Persistent Groin Pain Following Lichtenstein Repair. World J Surg. 2017; 41: 701712. Ref.: https://goo.gl/Q7EnW9

8. BD Chaurasia's Textbook of Human Anatomy. Vol-2, Fifth Edition. 223-226.

9. Lloyd DM, Sutton CD, Altafa A, Fareed K, Bloxham L, et al. Laparoscopic inguinal ligament tenotomy and mesh reinforcement of the anterior abdominal wall: a new approach for the management of chronic groin pain. Surg Laparosc Endosc Percutan Tech. 2008; 18: 63-68. Ref.: https://goo.gl/8wmF9i

10. Mui WL, Ng CS, Fung TM, Cheung FK, Wong CM, et al. Prophylactic ilioinguinal neurectomy in open inguinal hernia repair: a double-blind randomized controlled trial. Ann Surg. 2006; 244: 27-33. Ref.: https://goo.gl/kWxSsx

11. Boswell SG, Cole BJ, Sundman EA, Karas V, Fortier LA. Platelet-rich plasma: a milieu of bioactive factors. Arthroscopy. 2012; 28: 429-439. Ref.: https://goo.gl/BCtYCd 